\title{
Histopathological Diagnostic Dilemma in Retrorectal Developmental Cysts: Report of a Case and Review of the Literature
}

\author{
Meltem AZATÇAM' ${ }^{1}$, Eren ALTUN' ${ }^{1}$, Veli AVCI ${ }^{2}$
}

'Department of Medical Pathology, '2Department of Pediatric Surgery Clinics, Bingöl Maternity and Children's Hospital, BINGÖL, TURKEY

\begin{abstract}
Retrorectal developmental cysts are lesions that are classified according to their histopathological characteristics and origins. The major types are epidermoid cyst, dermoid cyst, rectal duplication cyst, rectal cystic hamartoma and teratoma. These cysts grow slowly and the majority of cases are asymptomatic. Total excision is required and histopathological examination should be carefully performed for retrorectal localized developmental cysts, since the cystic lesions may show malignant transformation. Here, a 3-year-old male patient with retrorectal mass, which was histopathologically compatible with tailgut cyst, is presented and the differential diagnosis of retrorectal developmental cysts is discussed.
\end{abstract}

Key Words: Cyst, Developmental, Duplication, Rectal

\section{INTRODUCTION}

Retrorectal developmental cysts are smooth-bordered, thin walled and unilocular/multilocular cystic lesions that are classified according to their histopathological characteristics and origins. They are though to originate from caudal embryonic remnants. Developmental cysts, most of them being congenital, are lesions frequently localized in the retrorectal region $(1,2)$. The major types of retrorectal cysts are epidermoid cyst, dermoid cyst, rectal duplication cyst, rectal cystic hamartoma and teratoma (35). Tailgut cyst, also known as retrorectal cystic hamartoma, is a congenital lesion of embryologic tailgut origin, located in the retrorectal space $(2,4,6)$. Rectal duplication cysts are rare lesions that constitute $5 \%$ of all developmental cysts (8). Developmental cysts are seen more frequently in females than males (3:1) during childhood and young adulthood $(2,7)$. Most cases are asymptomatic. They can rarely be diagnosed in newborns and infants when they cause a macroscopic lesion detectable during physical examination such as rectal prolapsus $(7,9)$. These cysts, usually having a multilocular structure, may be lined by respiratory, squamous, transitional, columnar, ciliated columnar, mucinous and gastrointestinal epithelium. Some of them contain organized/disorganized smooth muscle bundles, located under the epithelium. Except for epidermoid/dermoid cysts, the lumen is filled with mucin or gelatinous material. Granulomatous inflammation and foreign body-type giant cell reaction may be observed in

(Turk Patoloji Derg 2018, 34:175-178)

Received : 09.03.2015 Accepted : 05.05.2015 tailgut cysts $(4,6,10)$. Complications such as infection, fistula formation or malignancy development have been reported in developmental cysts $(2,7,11)$. We aimed to present our 3 -year-old male patient who had a retrorectal located cyst that caused intestinal prolapsus through the anus.

\section{CASE REPORT}

A 3-year-old male patient presented to the pediatric surgery outpatient clinic with the complaint of prolapsed intestine through anus. In his physical examination, a fluctuating cystic mass was palpated under the intestinal mucosa of the prolapsed intestinal segment. Following aspiration of the cyst by a needle and draining viscous, transparent fluid with a mucoid nature, the mass was surgically excised.

The specimen received by our pathology laboratory was $2.3 \times 1.0 \times 0.7 \mathrm{~cm}$ in size. Macroscopically, one side of the specimen had mucosal characteristics with white/pink color and a smooth appearance while the other side had an irregular appearance. The entire specimen was processed following staining of the irregular surface with Indian ink. On light microscopic evaluation, the full-thickness colon wall had an organized structure at one side, and continued with loose fibrous connective tissue and the cystic lesion adjacent to the colon wall (Figure 1A,B). The microscopic examination of the cyst wall showed granulation tissue and patchy columnar and respiratory epithelium, with scattered inflammatory cells under the epithelial surface in most of the areas, together with a muscular layer continuing throughout

Correspondence: Eren ALTUN

Bingöl Kadın Doğum ve Çocuk Hastalıkları Hastanesi, Patoloji Laboratuvarı, BİNGÖL, TURKEY

E-mail: erenaltun@hotmail.com Phone: +90 5303411651 
the entire lesion. In focal areas, several small, tubular, and gland-like structures were noted (Figure 1A,B,2). Except for the actual intestinal wall, no neural plexus was observed in areas matching the cyst wall. Immunohistochemical studies revealed cytoplasmic immunoreactivity with cytokeratin 7 in the cyst epithelium, while there was no reaction with cytokeratin 20. Thyroid transcription factor-1 showed
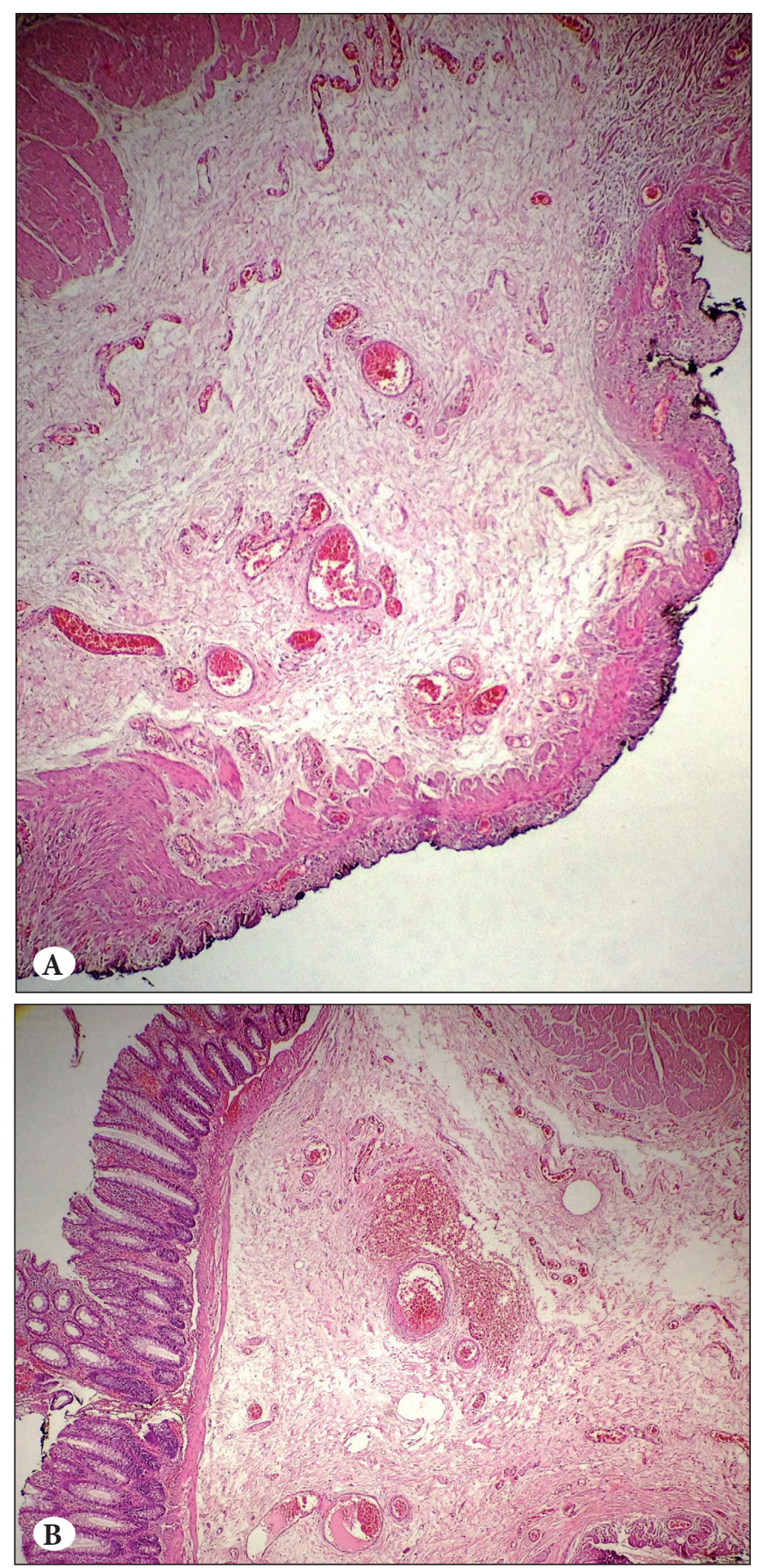

Figure 1: A) Cyst wall and muscularis propria of the intestine. B) Organized, full-thickness intestinal wall (H\&E; x40). sparse nuclear immunoreactivity. Focal immunoreactivity was observed with synaptophysin and neuron-specific enolase on the cyst wall, which could not be interpreted to be in favor of a plexus. No reaction was detected with chromogranin. Based on the histopathological and immunohistochemical results, the case was interpreted as a tailgut cyst.

\section{DISCUSSION}

Developmental cysts of the rectal region are smooth-bordered, thin-walled, unilocular/multilocular cystic lesions, which are classified according to their histopathological characteristics and origins. Since these cysts are slowly growing masses, most cases are asymptomatic and are diagnosed incidentally. Constipation, bleeding, perineal pain, and feeling of fullness become manifest with increasing cyst size. Infected cysts may cause perianal abscess and fistulas. Malignancy development has been rarely reported $(2,4,7,10)$.

Epidermoid cyst, dermoid cyst, duplication cyst, cystic hamartoma (tailgut) and teratoma are considered in the differential diagnosis of cystic lesions of the rectal region $(4,5)$. Imaging techniques such as ultrasonography, computerized tomography and magnetic resonance imaging are performed for the differential diagnosis of retrorectal cystic lesions. However, the differential diagnosis is quite difficult by radiological methods (12) and the definitive diagnosis is made by histopathological examination, in association with the clinical and radiological findings $(12,13)$.

Epidermoid cyst is unilocular, lined by squamous epithelium that contains no skin adnexa, and has no smooth muscle in its wall. In dermoid cyst, unlike epidermoid cyst,

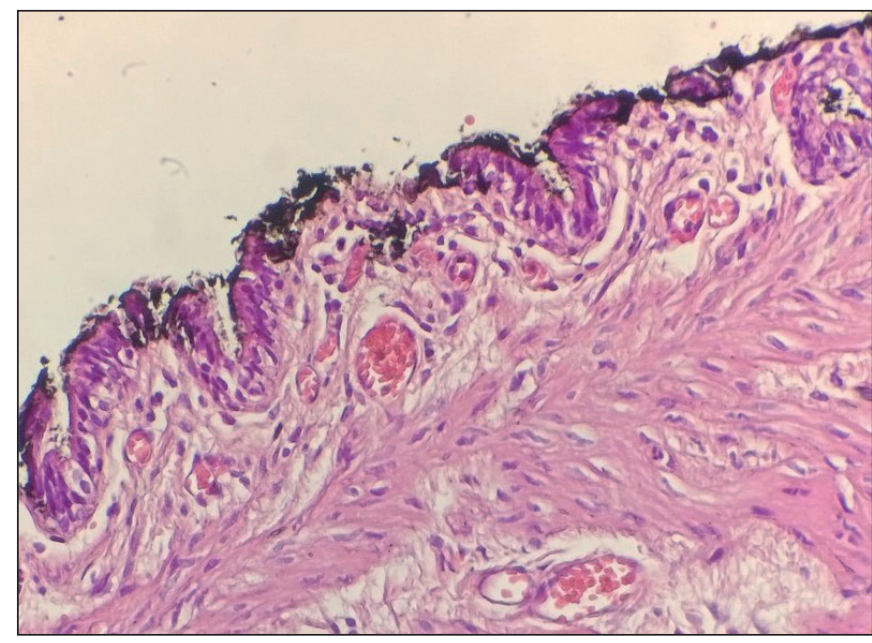

Figure 2. The cyst wall, with the surface lined by respiratory epithelium and underlying muscle layer (H\&E; x100). 
skin adnexa are observed under the squamous epithelium. Duplication cyst is unilocular, and lined by respiratory and gastrointestinal epithelium; its wall contains two organized muscle layers (muscularis mucosa and muscularis propria) together with neural plexus. Rectal cystic hamartomas (tailgut) are generally multilocular, and may be lined by squamous, transitional, columnar, ciliated columnar and mucinous epithelium; they contain disorganized smooth muscle bundles under the epithelium. Teratomas are lesions containing tissues of all three germ layers, and are usually unilocular $(4-6,10)$. In our case, columnar and respiratory epitheliums were present at the surface and an organized and thin structure consistent with muscularis mucosa was noted under the epithelium while absence of an organized muscularis propria of the cyst was noteworthy.

Among developmental cysts, the duplication cyst is one that is most frequently associated with complex genital and urinary system anomalies (3). A 12-year-old patient, having findings of disease and malformation accompanying tailgut cyst has also been reported in the literature (14). No associated anomaly was detected in our patient.

In classical textbooks, retrorectal cystic hamartoma is reported to be more frequent in children, young adults, and females $(2,10)$. According to the literature, the age range of retrorectal hamartoma is $0-80$ years (7). Although it is congenital, the average age for diagnosis of this lesion has been reported as 36 years (10); however, tailgut cysts have been reported in a newborn patient in the literature (7). Since our case was a 3-year-old male patient, he belonged to the group that manifests symptoms in the early period, when the literature is taken into consideration.

Developmental cysts that were fistulized and had solid components, or which developed malignancies such as adenocarcinoma and neuroendocrine carcinoma have also been reported $(2,7,11,15)$. Our case was entirely cystic in nature, having no solid component. No finding in favor of malignancy was detected.

Tailgut cysts are cystic lesions that develop from the tailgut and embryological remnants of neuroenteric canal, and are located in the presacral-retrorectal space; they contain mucoid, gelatinous fluid, and are usually multilocular $(2,10)$. Duplication cysts, however, have unilocular structure (3). Our literature review revealed that tailgut cysts have been found to be retrorectal, with most cases having a multilocular structure. However, in one of the reported cases, the cyst was unilocular in structure and adenocarcinoma was diagnosed (11). In our case, the cystic lesion was again in a retrorectal location and showed a unilocular structure.
Histopathologically, tailgut cysts are lined by squamous, transitional, columnar, and ciliated columnar epithelium; scattered subepithelial muscle bundles are also observed. Duplication cyst is lined by epithelium of respiratory and gastrointestinal systems and it contains two layers of organized muscle layers $(3,5,6,10)$. In reports related to this topic, the cyst epithelium has similar features to those written in classical textbooks in most of the cases. However, there are reports describing ileal duplication cysts lined by gastrointestinal, respiratory, or patchy-form squamous epithelia in the literature (12). While the cyst surface was eroded in most of the areas in our case, it was lined by columnar and respiratory epithelium in focal areas and a single and organized muscle layer was observed under the surface epithelium in most of the areas. This has led us to the differential diagnosis of the cyst with a duplication cyst. However, when the diagnostic criteria of duplication cyst are taken into consideration, organized and two-layered muscle has to be taken into account. In our case, an intestinal wall with organized structure and loose connective tissue adjacent to the wall were observed; this continued with the organized muscle layer of the cyst. The epithelium of the cyst was eroded and showed inflammatory cells and small, congested vascular structures in most of the areas; in focal areas, the cyst surface contained columnar and respiratory epithelium. Absence of two-layered muscle decreased the possibility of duplication cyst as a diagnosis. However, as some reports have suggested, the probability of having a single and common muscularis propria created confusion in favor of a duplication cyst $(16,17)$. For this reason, the comment of "duplication cyst could not be excluded definitely" was added to our report.

In some cases, the histopathological information published in classical textbooks has been not sufficiently descriptive for the differential diagnosis of duplication cyst from rectal cystic hamartoma. In patients who are not supported by detailed clinical and radiological data, a difficulty in diagnosis is encountered. Retrorectal developmental cysts are lesions that may have malignant transformation and total excision with careful histopathological evaluation of the cyst is therefore mandatory.

\section{REFERENCES}

1. Dahan H, Arrive L, Wendum D, Ducou le Pointe H, Djouhri H, Tubiana JM. Retrorectal developmental cysts in adults: clinical and radiologic-histopathologic review, differential diagnosis, and treatment. RadioGraphics. 2001;21: 575-84. 
2. Killingsworth C, Gadacz TR. Tailgut cyst (retrorectal cystic hamartoma): Report of a case and review of the literature. Am Surg. 2005;71:666-73.

3. Petras RE, Gramlich LT. Nonneoplastic intestinal diseases. In: Mills, Stacey E. editors. Sternberg's diagnostic surgical pathology, 5th ed. Philadelphia: Lippincott Williams \& Wilkins; 2010. 135253.

4. Neale JA. Retrorectal tumors. Clin Colon Rectal Surg. 2011;24:149-60.

5. Glasgow SC, Dietz DW. Retrorectal tumors. Clin Colon Rectal Surg. 2006;19:61-8.

6. Hassan I, Wietfeldt ED. Presacral tumors: Diagnosis and management. Clin Colon Rectal Surg. 2009;22:84-93.

7. Akbulut S. Unusual cause of defecation disturbance: A presacral tailgut cyst. Eur Rev Med Pharmacol Sci. 2013;17:1688-99.

8. Alexiou G, Lianos G, Voulgaris S, Zigouris A. Sacrococcygeal neoplastic lesions. J Cancer Res Ther. 2013; 9: 343-7.

9. Akıllığlu İ, Yücesan S, Hiçsönmez A. Tailgut cyst (retrorectal cystic hamartoma) misdiagnosed and treated as rectal prolapse. 29. Ulusal Çocuk Cerrahisi Kongresi, Harbiye, İstanbul, 14-17 Mayıs 2011, P133 (Poster).

10. Fenoglio-Preiser CM, Noffsinger AE, Stemmermann GN, Lantz PE, Isaacson PG, Gastrointestinal Pathology: An Atlas and Text, 3rd ed. Philadelphia: Lippincott Williams \& Willkins; 2008.
11. Prasad AR, Amin MB, Randolph TL, Lee CS, Ma CK. Retrorectal cystic hamartoma: Report of 5 cases with malignancy arising in 2. Arch Pathol Lab Med. 2000;124:725-9.

12. Leigh Baumann J, Patel C. Enteric duplication cyst containing squamous and respiratory epithelium: An interesting case of a typically pediatric entity presenting in an adult patient. Case Reports in Gastrointestinal Medicine. 2014; 4. Available from: http://dx.doi.org/10.1155/2014/790326

13. Ünlü $M$, Özbilgin $M$, Sökmen S, Sarığlu S. Seromüköz bez yapıları içeren bir Tailgut kisti: Olgu sunumu. DEÜ Tip Fakültesi Dergisi 2010; 24:143-7.

14. Galluzzo ML, Bailez M, Reusmann A, Gonzalez R, de Dávila MT. Tailgut cyst (Retrorectal hamartoma): Report of a pediatric case. Pediatr Dev Pathol. 2007;10:325-7.

15. Blank G, Königsrainer A, Sipos B, Ladurner R. Adenocarcinoma arising in a cystic duplication of the small bowel: Case report and review of literature. World J Surg Oncol. 2012;10:55.

16. Park WH, Choi SO. Coincident occurrence of intestinal duplication cyst and type I and type II intestinal atresias. J Korean Surg Soc. 2009;77:69-71.

17. Husain AN, Stocker JT. Color Atlas of Pediatric Pathology. New York: Demos Medical Publishing; 2011. 